\title{
Laser welding of laser-structured copper connectors for battery applications and power electronics
}

\author{
Johanna Helm ${ }^{1}$ (D) $\cdot$ Adrian Schulz $^{2} \cdot$ Alexander Olowinsky $^{1} \cdot$ Andreas Dohrn $^{1} \cdot$ Reinhart Poprawe $^{1}$
}

Received: 28 October 2019 / Accepted: 6 January 2020 / Published online: 10 February 2020

(C) The Author(s) 2020

\begin{abstract}
The electrification of the automobile industry leads to an increasing demand for high-performance energy storage systems. The more complex the battery pack, the more complex the electronic components will become. Very high currents have to be transported in a short time and very fast electrical switching processes have to be made possible. These requirements have an effect on the required quality of the electrical connection. Furthermore, a joining process is required that offers short cycle times and a high degree of automation. Laser micro welding with fibre lasers $(1070 \mathrm{~nm})$ meets the requirements placed on joining technology. Due to the high beam quality, very small spot diameters and thus very high intensities can be achieved. Copper materials of high purity are used to achieve the high conductivity of the electrical connection. This material, in turn, poses a great challenge to the welding process, since the reflectance for the beam sources mentioned is above $95 \%$.

This paper presents a way of significantly reducing the reflectance for copper connectors and thus making the joining process more efficient. For this purpose, the copper connectors are first pre-processed with an ultrashort pulse laser process, which significantly increases the surface area. In a second step, bead-on-plate welds are carried out on the structured surfaces and the absorption coefficient is determined during the welding process with the aid of a double integrating sphere assembly in comparison to a bare copper sample.
\end{abstract}

Keywords Laser micro welding $\cdot$ Copper $\cdot$ Laser structuring $\cdot$ Absorption

\section{Introduction}

Nitrogen oxide pollution represents a health risk in the modern world. According to statistics from the Federal Environment Agency in Germany, the level of nitrogen oxide pollution has tended to decline over the past 15 years, but the limit values set by the EU Directive 2008/50/EC are still exceeded at more than half of the traffic-related measuring stations [1]. In metropolitan areas and urban regions, road traffic, and in

Recommended for publication by Commission IV - Power Beam Processes

Johanna Helm

johanna.helm@ilt.fraunhofer.de

1 Fraunhofer Institute for Laser Technology ILT, Steinbachstr. 15, 52074 Aachen, Germany

2 Naturwissenschaftlich Technische Akademie Prof. Dr. Gruebler gGmbH, Seidenstraße 12-35, 88316 Isny im Allgaeu, Germany particular motor vehicles with combustion engines, is the main cause of the high level of pollution.

One way of reducing nitrogen oxide emissions and thus improving the quality of life in urban areas is to concentrate increasingly on alternative driving concepts. In addition to the fuel cell, a battery electric drive provides a good opportunity to reach the limits of the EU directive in the future.

The heart of a battery electric vehicle (BEV) is the battery pack, which in turn consists of several hundred to thousand individual cells. Usually, cells based on lithium ion are used for this purpose. These individual cells are in turn connected to form modules and several of these modules then form a battery pack. In addition to the battery pack, many other electrical and electronic components are required, such as a battery management system (BMS). Due to their electrical conductivity, copper connectors are used as electrical connecting elements between the cells, modules and peripheral electronics. This results in a large number of joints that have to withstand thermal, mechanical and electrical loads. Electrical contacting therefore requires a joining process that guarantees a robust connection and at the same time offers short cycle 
times and high automation capability [2]. Laser micro welding with fibre lasers is a joining process that meets the aforementioned requirements. However, laser beam welding of copper is difficult due to material-specific properties [3, 4].

In this work, the surface of a copper connector is specifically modified by an upstream laser structuring process. In this way, functional structures are formed and the surface is enlarged. The aim is to reduce the influence of the materialspecific properties on the joining process and thus improve the absorption behaviour. This enables a more efficient and controllable joining process.

\section{State of the art}

\subsection{Laser ablation with ultrashort pulsed lasers}

The energy deposition during the irradiation of metals with ultrashort pulsed (USP) laser radiation is described by the socalled two-temperature model, in which the temperatures of the free electrons and the metal atomic lattice are described isolated from each other by two coupled differential equations [5-7]. This is necessary because the two systems are temporarily out of thermal equilibrium due to the short time scale on which the energy is deposited. For metals, the time scale on which the lattice is heated is a few picoseconds, which is much shorter than the time required for thermal expansion. Consequently, the heating of the irradiated volume is quasiisochoric [8-10]. The shock wave in the material accelerates and ablates a thin layer of the only partly molten material [11]. .Figure 1 shows a comparison between the ablation mechanisms for $\mu \mathrm{s} / \mathrm{ns}$ pulses with the mechanisms for USP-pulses (ps/fs).

In further comparison of $\mu \mathrm{s} / \mathrm{ns}$ pulses and USP-pulses, the thermal penetration depth $\delta_{\text {th }}$ is to be considered. This value is calculated by solving the heat equation, which describes how heat evolves in a solid medium. The thermal penetration depth represents the depth where the temperature of a solid medium drops to about $10 \%$ compared to the temperature of its heated surface.

$\delta_{t h}=\sqrt{4 \kappa \cdot t}$

$\delta_{\text {th }}$, thermal penetration depth $[\mathrm{mm}] ; \kappa$, temperature conductivity $\left[\mathrm{mm}^{2} / \mathrm{s}\right]$ and $\mathrm{t}$, time duration in which the surface is heated, in this case pulse length of the laser [s] [12-14].

Because of the time dependency, the thermal penetration depth of USP-pulses is significantly shorter than the penetration depth of $\mu \mathrm{s} / \mathrm{ns}$ pulses. The heat-affected zone in which ablation occurs is therefore much smaller in ablation processes with USP lasers. This behaviour leads to higher precision in the ablation process with shorter pulses. Laser radiation only interacts with electrons. Electron-/phonon interaction or even
Laser ablation with ns/ $\mu$ s pulses

Laser ablation with ps/fs pulses (USP)
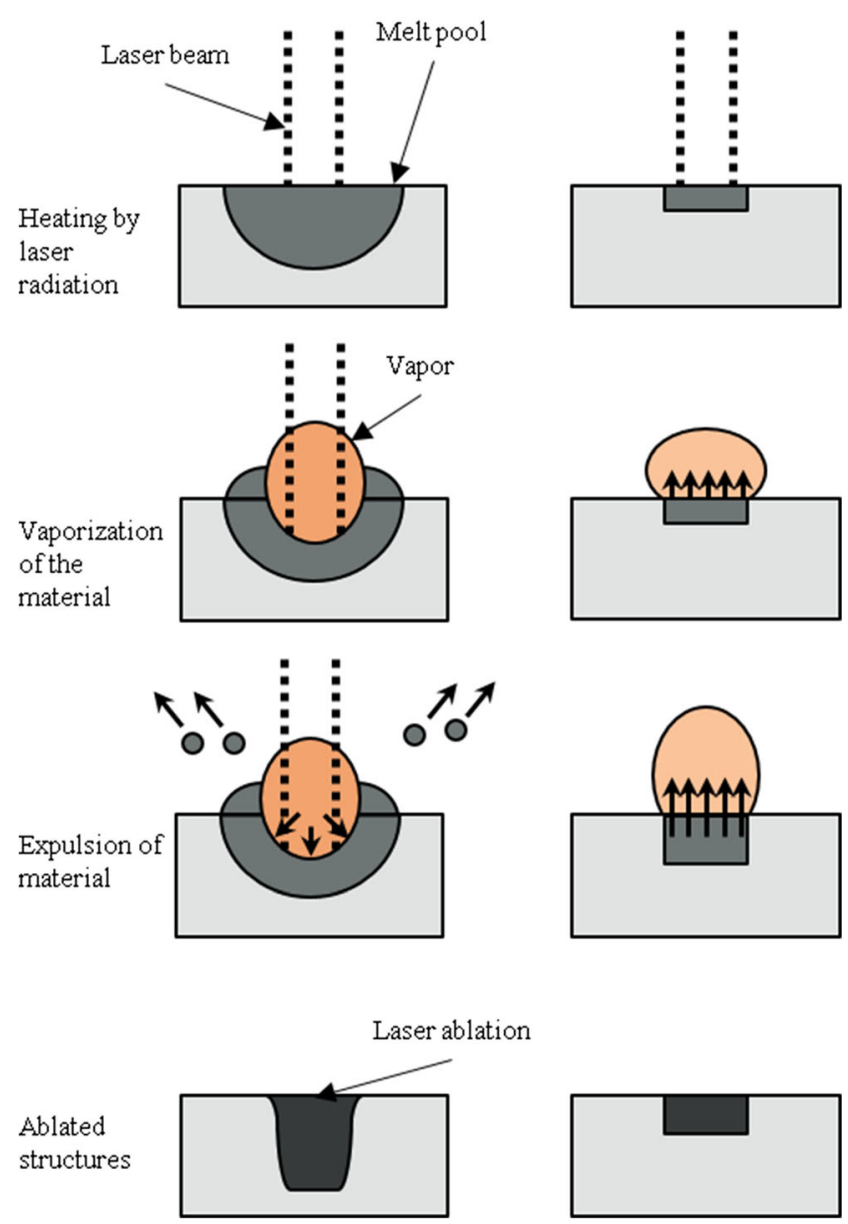

Fig. 1 Comparison between the ablation mechanisms with $\mu \mathrm{s} / \mathrm{ns}$ pulses and USP-pulses (ps, fs). Laser ablation with $\mathrm{ns} / \mu$ s pulses is a meltdominated process, whereas laser ablation with $\mathrm{ps} / \mathrm{fs}$ laser pulses (USP) is vapour-dominated process

phonon-phonon interaction only occurs after a time scale of 10 to $100 \mathrm{ps}$ [12]. In the case of USP-pulses, the lattice structure of the medium is heated after the laser or rather the pulse is shut off. This leads to no interaction between the laser pulse of the USP laser and the vapour or plasma of the ablation process [14].

\subsection{Laser beam welding}

Basically, two welding regimes are distinguished in the laser beam welding process: Heat conduction welding and deep penetration welding. In heat conduction welding, the surface of the material is melted, whereby the energy is transported into deeper layers via heat conduction [13]. The maximum achievable aspect ratio (welding depth to seam width) is therefore in the order 1:2. During deep penetration welding, the 
intensity of the radiation exceeds the threshold intensity and the material changes to a vaporous state. The vaporous material escapes from the base material, which leads to the formation of a counterforce in the depth direction of the material. This causes the formation of a vapour capillary (keyhole).

Within this keyhole, the incident beam is reflected several times, which increases the degree of absorption. The resulting aspect ratio can exceed 10:1. These two welding regimes are shown in Fig. 2.

\subsection{Welding of copper with highly brilliant laser beam sources}

Laser beam welding of copper materials represents a challenge due to the material-specific properties [16]. Copper

\section{Heat conduction welding}

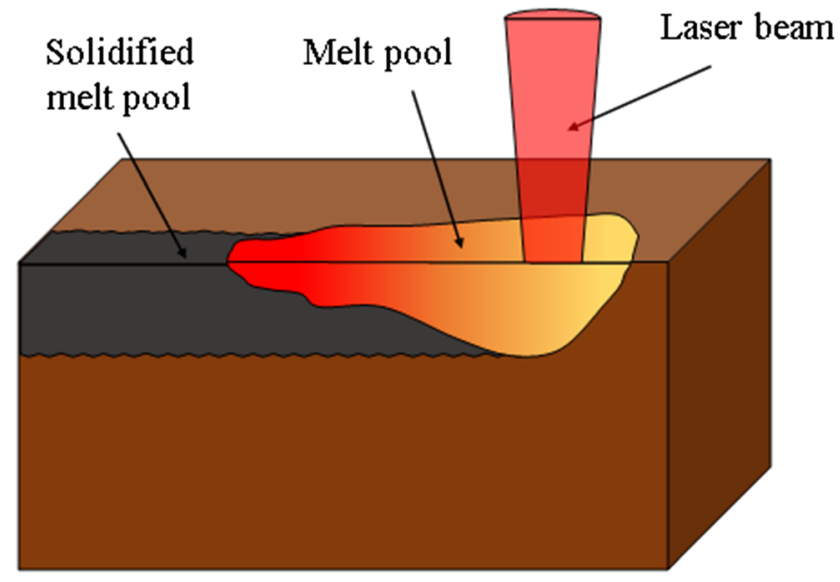

\section{Deep penetration welding}

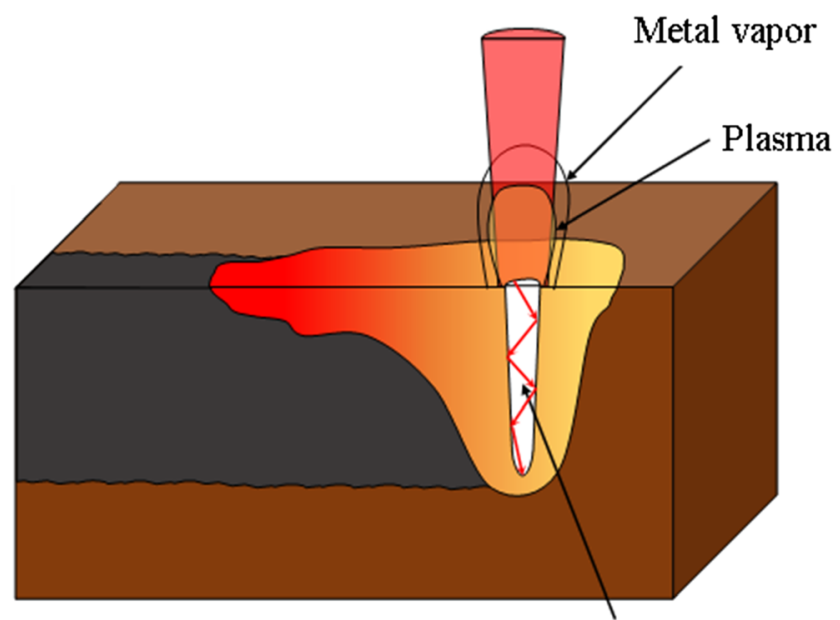

Keyhole

Fig. 2 Heat conduction welding (top) and deep penetration welding (bottom) $[4,15]$ shows a high thermal conductivity $(394 \mathrm{~W} /(\mathrm{mK}))$ and low absorption rate at room temperature for wavelength ranges that include common beam sources such as $\mathrm{CO}_{2}$ lasers or Nd:YAG lasers (Fig. 3). Fibre laser sources typically have a wavelength of $1070 \mathrm{~nm}$. At room temperature, the absorption coefficient for these beam sources is approximately $5 \%$. When the copper is molten, the absorption rate increases to about $15 \%$ [17]. In contrast to beam sources which work with visible light, the high brilliance of near infrared (NIR) fibre laser beam sources is decisive for the possibility of melting copper. Due to the very good focusability, focal diameters of $<30 \mu \mathrm{m}$ are possible. With output powers in continuous wave operation within kilowatt range, intensities in the operating point of more than $1.4 \times 10^{6} \mathrm{~W} / \mathrm{mm}^{2}$ are reached. With these high intensities, it is possible to melt the copper and gain a deep penetration welding process. Multiple reflections within the keyhole further increase the absorption rate.

However, the back reflections at the beginning of the process that persist until the deep welding process is fully developed, can damage the optical elements and even the beam source itself. Furthermore, the relatively long phase of the process setup reduces the effective joining length of a copper weld seam.

\section{Experimental setup}

\subsection{Laser beam sources for laser structuring and welding of the samples}

For both laser processes, beam sources in the NIR range are used. An ultrashort pulsed Nd:YAG laser from EdgeWave $\mathrm{GmbH}$, Wuerselen, Germany, is used for laser structuring. This beam source can generate pulses within the picosecond range with a maximum pulse energy of $2 \mathrm{~mJ}$ and a maximum pulse frequency of $2 \mathrm{MHz}$. For the beam deflection, a galvanometer scanner system is used. The f-Theta lens has a focal

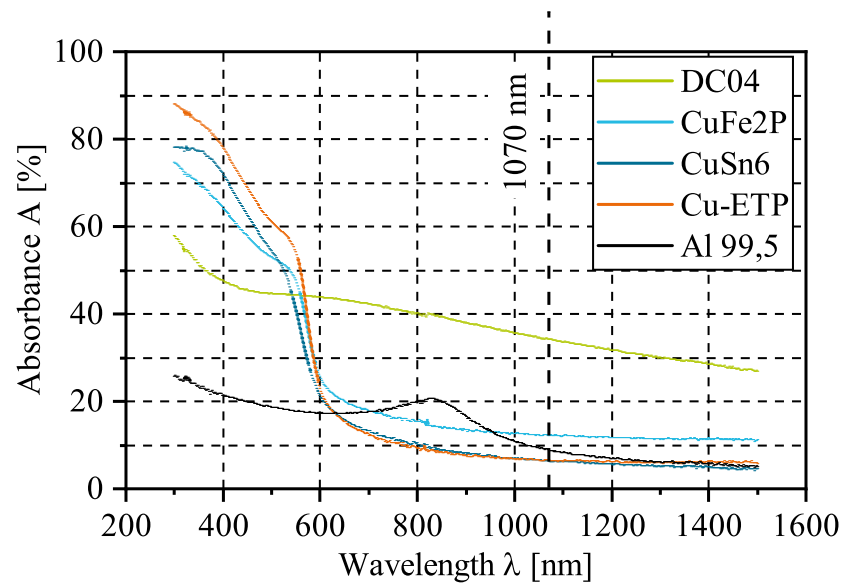

Fig. 3 Absorption rates of copper, copper alloys, aluminium and steel surfaces at room temperature over the wavelength 
length of $\mathrm{f}_{\mathrm{f}}=100 \mathrm{~mm}$, which generates a spot diameter of $25 \mu \mathrm{m}$. For the laser micro welding process, a fibre laser from SWS-Laser GmbH, Woerthsee, Germany, is used. This beam source has a maximum output power of $1 \mathrm{~kW}$ in continuous wave operation. A galvanometer scanner from Newson NV, Dendermonde, Belgium, is used for the laser beam deflection. The $\mathrm{f}$-theta lens has a focal length of $\mathrm{f}_{\mathrm{f}}=163 \mathrm{~mm}$ resulting in a spot diameter of approximately $46 \mu \mathrm{m}$. The most important data of the beam sources are stated in Table 1.

\subsection{Double integrating sphere for measuring the reflectance of the samples}

The assembly of two integrating spheres makes it possible to measure the reflected power during the welding process. The sample is placed in the sample holder of the lower integrating sphere (Newport Corporation, Irvine, USA). The laser beam first hits a beam splitter. Here, $90 \%$ of the irradiated power is transmitted, the remaining $10 \%$ is reflected. The transmitted radiation hits the copper sample. Diffusely reflected radiation is measured using a photodiode. Coaxially reflected radiation is reflected back onto the beam splitter. Here, again $90 \%$ of the coaxially reflected power is transmitted whilst the remaining $10 \%$ is reflected into the upper integrating sphere. The radiation is diffusely reflected at the sphere surface and detected with a photodiode [18]. Due to the complex design, a calibration is necessary to achieve reliable results. A schematic sketch of the structure is shown in Fig. 4.

\subsection{Preparation of the samples}

When copper or metals are structured, material is removed from the surface. This leads to an enlargement of the surface and, depending on the process, to periodic or non-periodic structures. The periodic structures are usually cones which are primarily created by crosshatching if the focal diameter is significantly smaller than the path distance. Nano-particles may be deposited on these cones during the ablation process.
These particles can also contribute to an increase in absorption. If the focal diameter is significantly larger than the path distance, random coral-like structures are formed [19, 20].

Surface structuring by laser ablation can significantly increase the absorption properties of the metals. The predominant effect is the formation of a geometric beam trap. As a result, incident radiation is reflected several times within the structure, thus increasing the degree of absorption. The shape and dimension of the structures and in particular the depth have a great influence on the absorption properties of the resulting surface. It has already been shown that this effect is not limited to a discrete wavelength spectrum, but affects all wavelengths from ultraviolet $(\sim 250 \mathrm{~nm})$ to the near infrared ( 2500 nm) [19-21].

\subsubsection{Laser structuring of the copper samples}

Copper sheets with a thickness of $600 \mu \mathrm{m}$ are used for the investigations. The surfaces are structured with the beam source described in Section 3.1. The modified area has a size of $10 \times 10 \mathrm{~mm}^{2}$. Different parameter sets are used to achieve two periodic (PS) and two non-periodic surfaces (NPS). Decisive parameters are the mean pulse power $\mathrm{P}_{\mathrm{m}, \mathrm{USP}}$, the pulse frequency $f_{U S P}$, the feed rate $v_{U S P}$, the number of passes $\mathrm{n}_{\mathrm{USP}}$, the path distance $\mathrm{l}_{\mathrm{USP}}$ and the path geometry. The parameters used are listed in Table 2.

An example of resulting copper samples is shown in Fig. 5. The structured area is clearly visible as it appears dark or black on the surface.

\subsubsection{Laser welding of the structured copper samples}

In order to measure the reflection of the laser-structured copper samples during the welding process, bead-on-plate seams are placed in three positions in the double integrating sphere structure described in Section 3.2. The bead-on-plate seams have a length of $5 \mathrm{~mm}$. In position A, welding takes place from the bare copper surface into the structured area. In
Table 1 Properties of the laser processing machines

\begin{tabular}{lll}
\hline Parameter & Laser structuring & Laser welding \\
\hline Manufacturer & EdgeWave & SWS-laser \\
Type of beam source & Nd:YAG, ultrashort pulsed & Fibre laser \\
Wave length & $1064 \mathrm{~nm}$ & $1070 \mathrm{~nm}$ \\
Maximum output power P & $14 \mathrm{~W}$ & $1000 \mathrm{~W}$ \\
Maximum pulse energy $\mathrm{E}_{\mathrm{USP}, \max }$ & $70 \mu \mathrm{J}$ & - \\
Pulse duration $\mathrm{T}_{\mathrm{P}}$ & $10 \mathrm{ps}$ & $\mathrm{cw}$ \\
Pulse frequency $\mathrm{f}_{\mathrm{P}}$ & $200-2000 \mathrm{kHz}$ & $\mathrm{cw}$ \\
Diffraction index $\mathrm{M}^{2}$ & $<1.5$ & $<1.1$ \\
Focal length $\mathrm{f}_{\mathrm{f}}$ & $100 \mathrm{~mm}$ & $163 \mathrm{~mm}$ \\
Focal diameter $\mathrm{d}$ & $25 \mu \mathrm{m}$ & $46 \mu \mathrm{m}$
\end{tabular}


Fig. 4 Double integrating sphere assembly for measuring the reflected radiation during laser welding

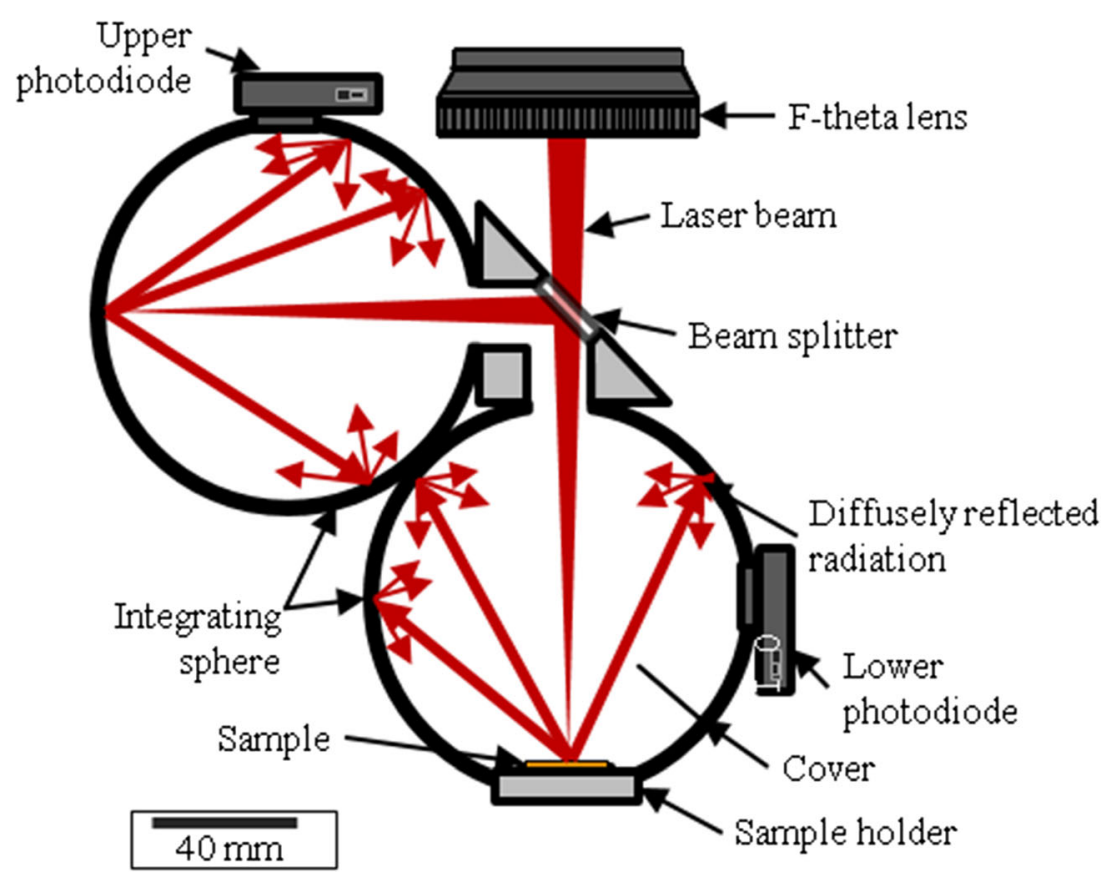

position $\mathrm{B}$, the weld seam starts on the structured surface and ends on the bare copper. In position $\mathrm{C}$, the entire weld lies on the structured surface. An overview of the arrangements is shown in Fig. 6.

The welding parameters are kept constant during welding. The reflected radiation is recorded. The following investigations are to be carried out on the behaviour of the reflected radiation:

- Can the back reflection at the beginning of the weld seam be reduced or completely suppressed by a laser-structured surface?

- Can the absorbed power over the weld seam be increased by laser structuring?

The parameters used are listed in Table 3.

For the sample NPS2, the laser power $\mathrm{P}_{\mathrm{L}}$ had to be reduced at position $\mathrm{C}$ to avoid damage to the integrating sphere.

\section{Results and discussion}

\subsection{Surface properties of the structured copper samples}

\subsubsection{Periodic structures}

The structured surfaces are examined in a scanning electron microscope of the type LEO 1455 EP from Carl Zeiss AG, Oberkochen, Germany. The images of the periodic structures are shown in Fig. 7. On the left hand side, pictures of the PS1 structures are shown in ascending magnification. On the right hand side, the SEM images of the PS2 structures can be seen.

The resulting surface of the PS1 sample consists of regular cones with a distance of $60 \mu \mathrm{m}$ (cf. Table 2). At the intersection points of the ablation geometry, the number of passes through the laser beam is twice as high as at the sides of the cones. As a result, the structure depth is particularly high here. The structures are measured using a VK-9700 Laser Scanning Microscope (LSM) from Keyence AG, Osaka, Japan. This measurement results in a depth of the resulting structures of up to $90 \mu \mathrm{m}$.

The PS2 samples were manufactured with a smaller path distance $1_{\text {USP }}$ of $30 \mu \mathrm{m}$. This distance is only five micrometres larger than the focal diameter of the USP laser $\left(\mathrm{d}_{\mathrm{USP}}=25 \mu \mathrm{m}\right)$. For this reason, the cones are not as well separated from each other as with the PS1 sample. A deeper trench is visible in the y-direction than in the $\mathrm{x}$ direction. This is the last process direction of the laser beam during the structuring process. The reason for this effect probably lies in the smaller path distance, which means that the tips of the cones have melted off more than in PS1. As a result, material has solidified on the sides so that a continuous connection is formed. Upon closer inspection, this effect can also be seen in PS1, but is not quite as prominent due to a greater path distance. The depth of the PS2 structures is about $40 \mu \mathrm{m}$.

\subsubsection{Non-periodic structures}

For the generation of non-periodic structures, path distances are selected that are significantly smaller than the focal diameter of the USP laser beam source. SEM 
Table 2 Parameters used for generating structured surfaces. Periodic structures are named $P S$ whilst non-periodic structures are named NPS

\begin{tabular}{lllllll}
\hline Designation & $\mathrm{P}_{\mathrm{m}, \mathrm{USP}}[\mathrm{W}]$ & $\mathrm{f}_{\mathrm{USP}}[\mathrm{kHz}]$ & $\mathrm{v}_{\mathrm{USP}}[\mathrm{mm} / \mathrm{s}]$ & Path geometry & $\mathrm{n}_{\mathrm{USP}}[-]$ & $1_{\mathrm{USP}}[\mu \mathrm{m}]$ \\
\hline PS1 & 2.6 & 200 & 4000 & Crosshatch & 2000 & 60 \\
PS2 & 2.6 & 200 & 4000 & Crosshatch & 2000 & 30 \\
NPS1 & 0.3 & 200 & 20 & Parallel & 1 & 5 \\
NPS2 & 0.3 & 200 & 20 & Parallel & 1 & 2 \\
\hline
\end{tabular}

pictures of the resulting surfaces are shown in Fig. 8. For the NPS1 structures, the track spacing is $5 \mu \mathrm{m}$ and for the NPS2 structures only $2 \mu \mathrm{m}$. This leads to the formation of re-deposited structures that were formed from the gas and plasma cloud during the ablation process. These particles are not homogeneously distributed and coral-like surfaces are formed from agglomerated material. On the one hand, this can be beneficial to the subsequent welding process, since the undercuts that result can make the beam trap particularly efficient, on the other hand, characterization is very difficult due to the irregularity of the surface. Measurements result in structure depths of up to $41 \mu \mathrm{m}$ for the NPS1 surface. The agglomerated structures of the NPS2 surface are on average smaller (see Fig. 8) and more delicate. The measured structure depth is also less than for the NPS1 sample and is about $31 \mu \mathrm{m}$.

\subsection{Reflectance of the structured samples measured by UV-VIS spectroscopy}

The reflectance $\mathrm{R}$ at room temperature is also an important parameter for characterizing the structured surfaces. If the reflectivity can already be significantly reduced at room temperature, less radiation is reflected coaxially at the beginning of the welding process and the probability of damage to the optical elements or the beam source is reduced. Furthermore, the process becomes more efficient because more radiation is absorbed at the beginning and the deep welding process starts earlier. The measurement is performed with a Lambda 1050 spectrometer from PerkinElmer Inc., Waltham, USA. The spectrometer is calibrated with a white standard, which allows the absolute reflectance to be measured. An untreated copper sample serves as a reference. In addition to laser micro welding with fibre lasers, the use of blue $(450 \mathrm{~nm})$ and green $(515 \mathrm{~nm})$ beam sources is currently the subject of research, since these have a higher absorption coefficient for copper than fibre lasers. To determine whether a structuring process also has effects on the reflection of blue and green radiation, the reflection spectrum of the surface structures is measured from 400 to $1100 \mathrm{~nm}$. In Fig. 9, the reflectance of the samples is shown as a function of the wavelength.

Over the entire measured spectrum, the reference surface has the highest reflectance of about $98 \%$. The qualitative course is similar for all examined surfaces. At a wavelength of $550 \mathrm{~nm}$ to about $570 \mathrm{~nm}$, the curves show a bend and the reflectance increases more strongly over the course of time. This change in reflectivity is significantly reduced by the surface structures, where the curve is not as steep. The NDS1 surface has the lowest reflectance at all measured wavelengths. For the processing wavelength of the fibre laser $(1070 \mathrm{~nm})$, the reflectance can be reduced to $12.3 \%$ with the NPS1 structures. This reduces the reflectance by $87.6 \%$ compared to the reference sample. The difference between the two periodic surface structures is particularly obvious. PS1 has a reflectance of about $20 \%$ at the processing wavelength, whilst PS2 still reflects about $50 \%$ of the incident radiation. If one compares these values with the SEM images (Fig. 7), it becomes clear that the partially missing trenches between the cones homogenize the surface to such an extent that the effect of a resulting beam trap is significantly less effective than with PS1 samples. When comparing the reflectance of the structured samples at the processing wavelength, the non-periodic structures appear more suitable to reduce the reflectivity in laser micro welding and to increase the efficiency of the process.
Fig. 5 Photo of a structured copper sample. The structured area appears dark or black on the surface

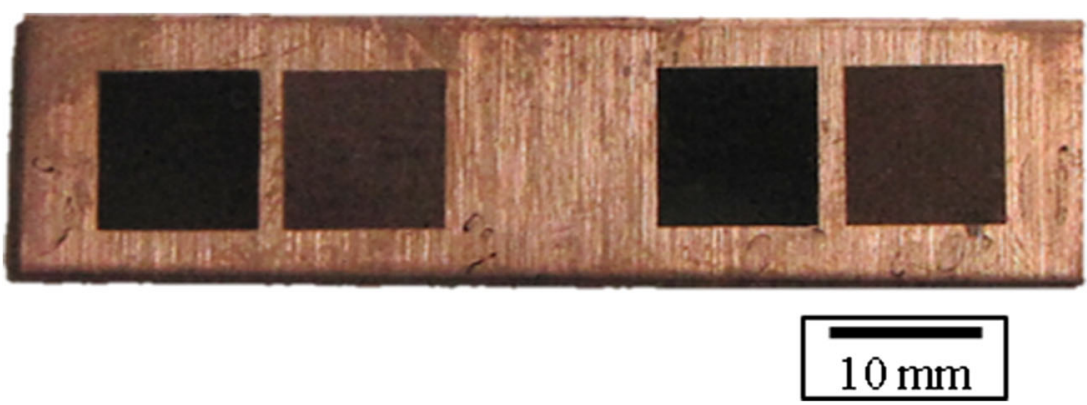



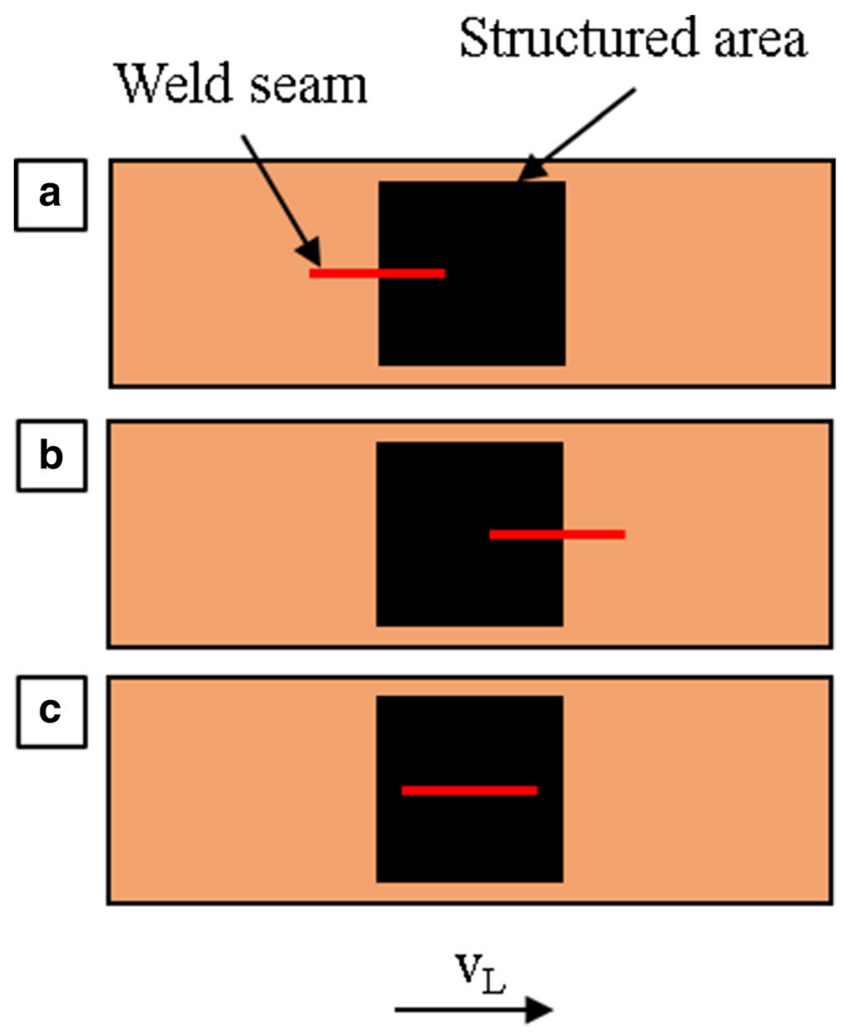

Fig. 6 Position of the bead-on-plate welds on the copper samples

\subsection{Reflectance during laser micro welding of the structured samples}

The measurement of the reflected power during laser beam micro welding is intended to show whether laser structuring of the copper samples is suitable both for reducing the initially reflected power at the start of the process and also for increasing efficiency during the entire welding process. The double integrating sphere design from Section 3.2 is used for this purpose. The proportion of the reflected radiation is determined by

$R_{R}=\frac{P_{R}}{P_{L}}$

$\mathrm{R}_{\mathrm{R}}$, proportion of reflected radiation [-]; $\mathrm{P}_{\mathrm{R}}$, reflected laser power [W]; $\mathrm{P}_{\mathrm{L}}$, laser power [W].

Table 3 Parameters for the laser welding process are set constant during all experiments

\begin{tabular}{ll}
\hline Parameter & Value \\
\hline Laser power $\mathrm{P}_{\mathrm{L}}$ & $585 \mathrm{~W} / 495 \mathrm{~W}$ (NPS2, C) \\
Linear feed rate $\mathrm{v}_{\mathrm{L}}$ & $70 \mathrm{~mm} / \mathrm{s}$ \\
Oscillation amplitude $\mathrm{A}_{\mathrm{L}}$ & $0.05 \mathrm{~mm}$ \\
Oscillation frequency $\mathrm{f}_{\mathrm{L}}$ & $2000 \mathrm{~Hz}$ \\
Length of weld lines $\mathrm{l}_{\mathrm{L}}$ & $5 \mathrm{~mm}$ \\
\hline
\end{tabular}

This results in the degree of coupling

$\eta=1-R_{R}=1-\frac{P_{R}}{P_{L}}$

$\eta$, degree of coupling [-].

In addition, it will be investigated whether the influence of the surface structures in line welding changes over the process time and the process progress. The three weld seam positions from Section 3.3.2 are used for this purpose.

\subsubsection{Periodic structures}

Figure 10 shows the reflected power $\mathrm{P}_{\mathrm{R}}$ of the PS1 sample over time for the weld positions A, B and C. At weld position $\mathrm{A}$, the weld seam starts on the untreated copper surface and proceeds into the structured area. At the beginning of the process, a clear maximum of $P_{R}$ is visible. The bare copper reflects a large part of the radiation (cf. Fig. 9). When the laser welding process changes to deep penetration welding, more power is absorbed by the hotter material and the multiple reflections in the keyhole contribute significantly to increased efficiency $(\mathrm{t} \approx 5 \mathrm{~ms})$. After about $30 \mathrm{~ms}$, the laser beam crosses over to the structured area of the sample, during which the reflected power continues to decrease. The coupling degree $\eta$ is now $71 \%$. When comparing the curve of the reflected power $P_{R}$ on the bare copper surface with the one on the structured surface, the process on the patterned surface is smoother. This observation is confirmed when looking at the weld seam bead, which is smooth and regular on the structured surface.

At weld position B, the course of the weld seam was reversed. It starts on the structured surface and then continues on the area of the untreated copper sample. Especially in comparison to position $\mathrm{A}$, the initial back reflection can be completely eliminated. The process quickly changes to deep penetration welding and shows a very constant course of the reflected power. At the crossover to the area of untreated copper, the coupling degree drops from 69 to $63 \%$. However, the deep penetration welding process is sustained after the change. On the untreated copper, the process is significantly smoother compared to position A. This suggests that starting the welding process on a structured surface can have a positive effect on the development of the process. At weld position C, it was investigated whether the process flow of a laser micro welding process on a structured surface changes over the seam length. The result shows a very constant course with a coupling degree of $71 \%$ and a very smooth and regular seam pattern.

The reflected power $\mathrm{P}_{\mathrm{R}}$ of the PS2 sample over time for the weld positions A, B and C is shown in Fig. 11. For weld position A, at the beginning of the process, (as seen for PS1) 
Fig. 7 SEM images of the periodic surface structures
PS1
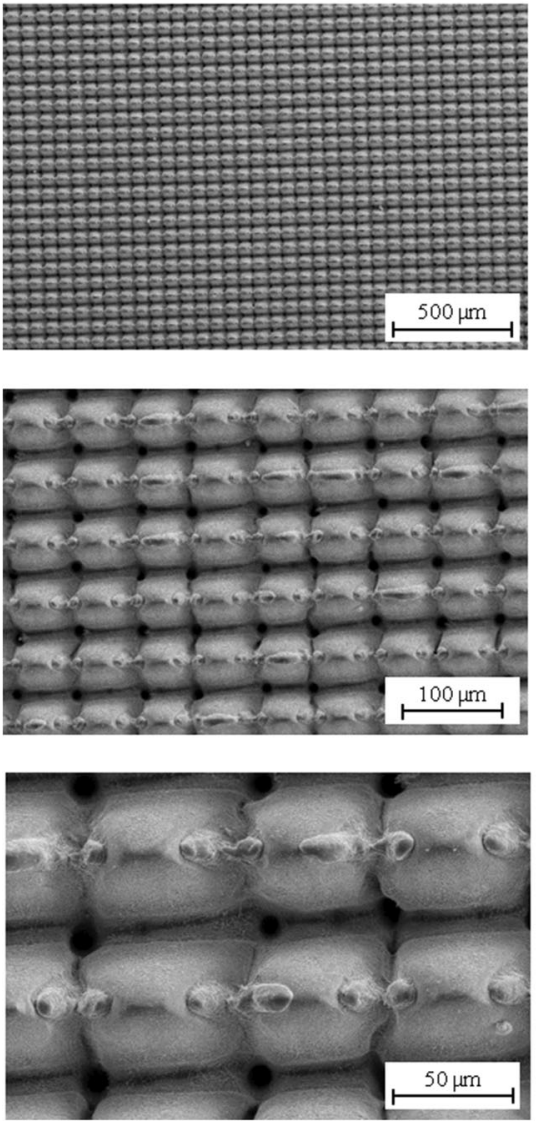

PS2
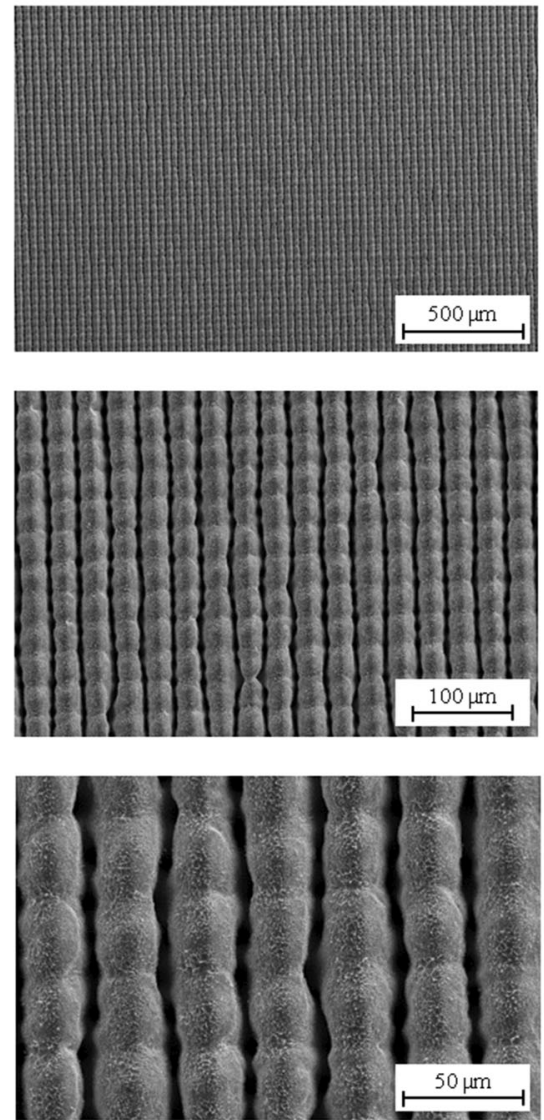

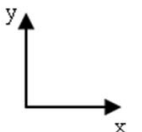

a clear maximum of the reflected power can be seen. The crossover onto the structured area of the sample here is approximately at $\mathrm{t}=38 \mathrm{~ms}$. The welding process on the untreated copper surface is not stable, and the course of the reflected power $P_{R}$ decreases over time. In the range between the two surface qualities, the coupling degree $\eta$ increases. At the edge of the structured area, the surface is undefined and not as regular as in the middle of the structured area. Here, particles from the gas and plasma phases can deposit and contribute to increased absorption for a short time. On the structured surface, the curve is constant again and a coupling degree of $67 \%$ results. As with PS1, the appearance of the weld seam bead is uniform and smooth.

As with PS1, the initial back reflection (seam position B) can also be suppressed with PS2 samples. The course of the reflected power is constant and hardly changes during the crossover to the unstructured area. This suggests that the PS2 structures are not suitable for increasing the efficiency of the entire welding process, since the degree of coupling $\eta$ between the structured and untreated surface hardly changes during the process. However, this structure is suitable for eliminating the initial back reflection. In seam position $\mathrm{C}$, a constant course of the reflected radiation can be seen with only very small fluctuations. The seam surface is uniform and smooth.

\subsubsection{Non-periodic structures}

Figure 12 shows the reflected power curve for the nonperiodic sample NPS1 for seam positions A, B and C. At the beginning of seam position $A$, the initial back reflection is visible as already seen with the periodic samples. After a deep welding process has developed, the course of the reflected power is constant until at $\mathrm{t} \approx 35 \mathrm{~ms}$ the crossover into the structured area of the sample occurs. Here, the coupling degree changes from 63 to $87 \%$ and remains constant until the end of the weld seam. On the surface of the structured area, weld spatters can be seen. Due to the high degree of coupling in this area, the weld pool overheats so that spatters are released from the weld pool.

At seam position $B$, a peak is visible at the beginning of the graph. This peak is not as large as on the untreated copper side, but nevertheless occurred during all measurements. However, this effect does not occur at seam position C. In subsequent investigations, high-speed images of the laser welding process will be taken, which may explain this phenomenon. Further in the course, the coupling degree is constant at $86 \%$ and decreases to $66 \%$ at the crossover to the untreated surface. Seam position $\mathrm{C}$ shows a constant course of the coupling degree at $84 \%$. Surrounding weld spatters 
Fig. 8 SEM images of the nonperiodic surface structures
NPS1
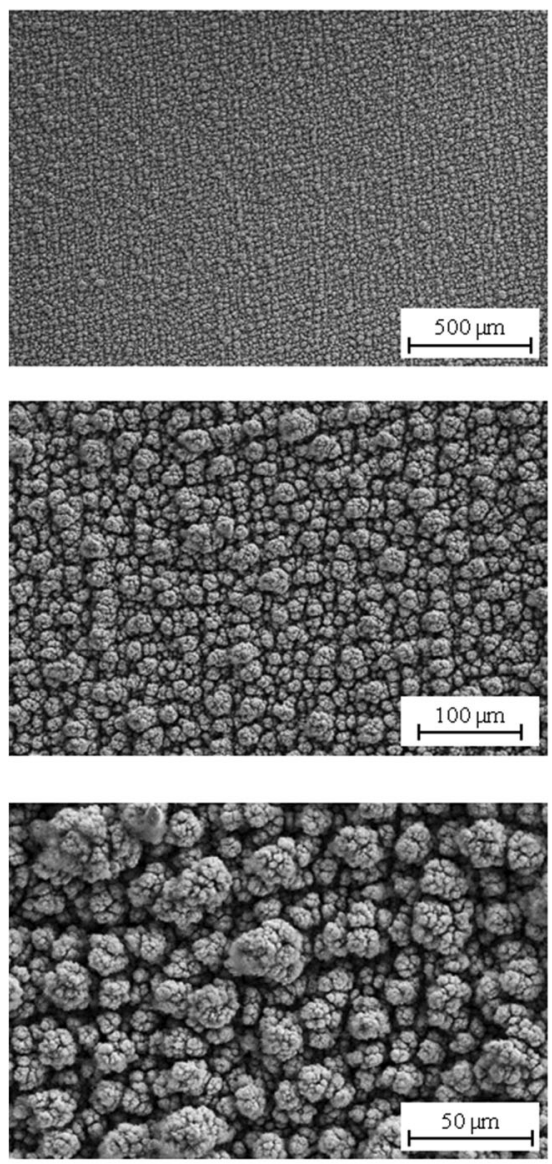

NPS2
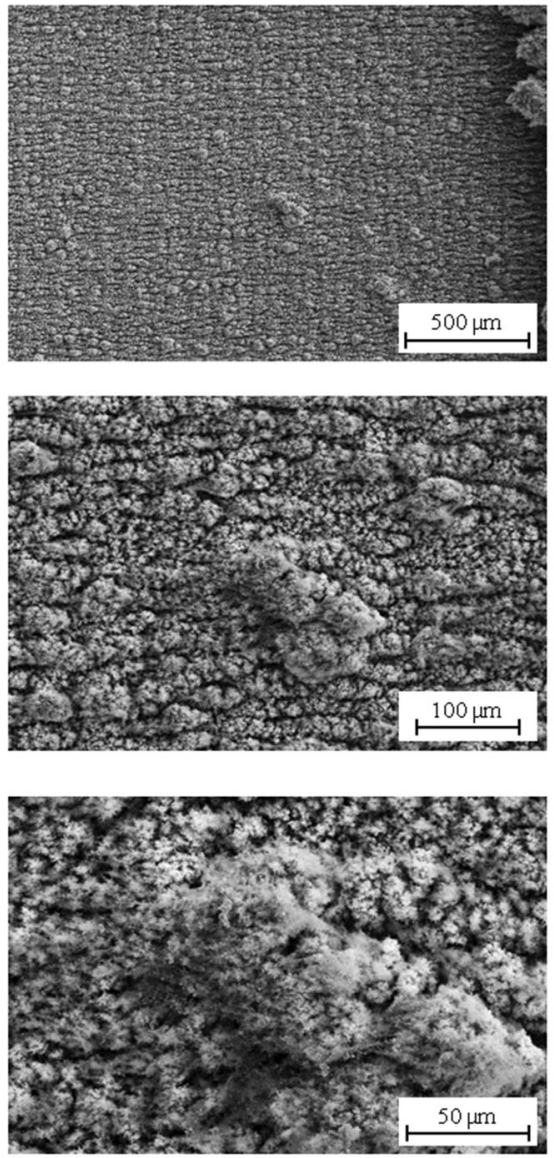

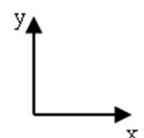

indicate an overheating of the melt pool. This type of structuring is well suited for increasing the efficiency of laser micro welding. Compared to untreated copper surfaces, the irradiated power can probably be significantly reduced.

During laser micro welding on the untreated copper surface at weld seam position A for the NPS2 samples, a very unsteady process can be seen. (Fig. 13) A constant deep penetration welding process does not develop. At the

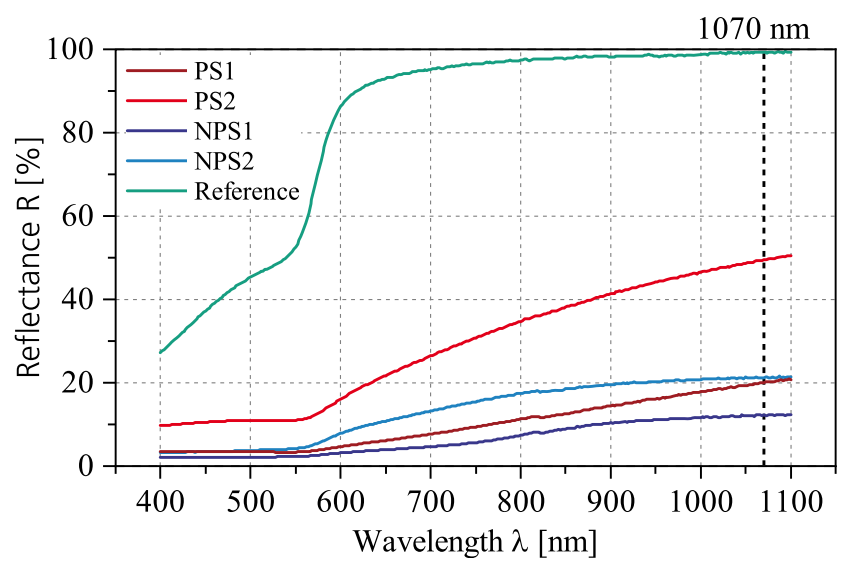

Fig. 9 Reflectance of the laser-structured sample and an untreated copper sample measured with an UV-Vis crossover to the structured area, the degree of coupling initially increases and then reaches a value of $75 \%$ when a constant deep penetration welding process is formed. In the transition area, the process is very unsteady. At weld seam position $\mathrm{B}$, this phenomenon is not visible. The previous unsteady process is most likely responsible for the course in the crossover area. If there is a sudden change in the reflection on the surface and a change in the topography, these effects overlap with previously existing fluctuations in the keyhole. At weld seam position B, as before, no initial peak is recognizable; the coupling degree decreases from 75 to $65 \%$ at the transition from the structured area to the untreated area. For seam position $\mathrm{C}$, the laser power $\mathrm{P}_{\mathrm{L}}$ had to be reduced (cf. Table 3) in order to avoid damage to the integrating sphere by metal vapours and spatters. The coupling degree here is $70 \%$. The weld beads show no weld spatters and have a regular appearance. Due to the reduced laser power $\mathrm{P}_{\mathrm{L}}$, however, comparability is not possible without restrictions.

The NPS2 samples are well suited to increase the efficiency of a laser welding process. In the course between the structured and the untreated copper surface, there is a clear change in the reflected power, and thus an increase in efficiency. 

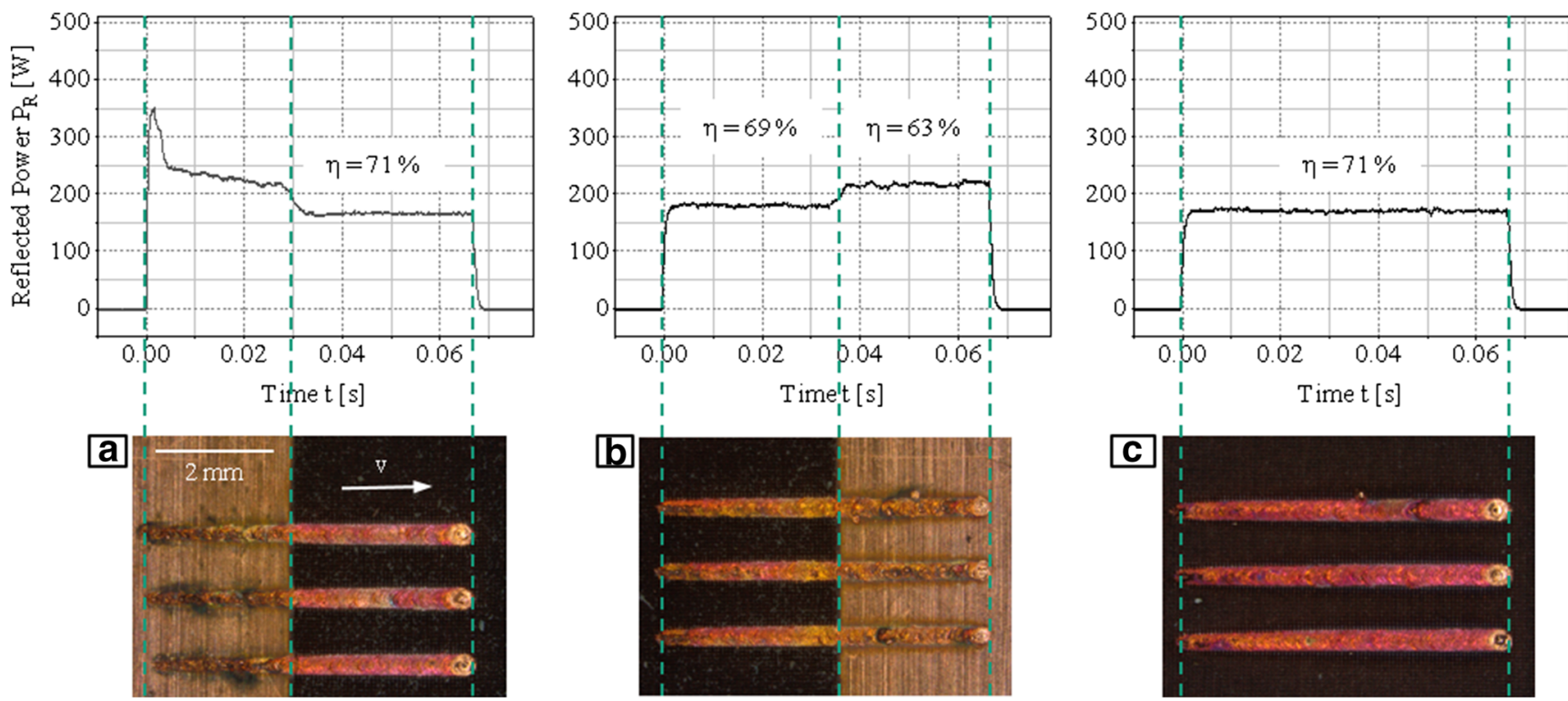

Fig. 10 Course of the reflected power $P_{R}$ of the PS1 samples over the weld seam length for weld seam positions, B and C

\section{Summary}

This work investigates the possibility of increasing the efficiency of a laser beam micro welding process by using surface structures. For this purpose, surface structures are generated on copper samples, which allow a broadband reduction of the reflectance. Bead-on-plate welding is then carried out on the laser-structured surfaces with simultaneous measurement of the reflected laser power.

With laser structuring, two different surface types are possible using a USP laser. On the one hand, periodic structures are generated which are created using path distances larger than the focal diameter. With a focal diameter of $25 \mu \mathrm{m}$, path distances of $60 \mu \mathrm{m}$ (PS1) and $30 \mu \mathrm{m}$ (PS2) are selected. If the path distance is significantly smaller than the focal diameter, non-periodic structures are formed from re-deposited material. Here, track distances of $5 \mu \mathrm{m}$ (NPS1) and $2 \mu \mathrm{m}$ (NPS2) are selected. By surface structuring, the reflectance of $\mathrm{Cu}$-ETP at room temperature can be reduced over a wavelength range from 400 to $1100 \mathrm{~nm}$. The lowest reflectance is achieved with the surface NPS1 over the entire measured spectrum. At the wavelength of the fibre laser, which was used for welding $(1070 \mathrm{~nm})$, the untreated surface used as a reference has a reflectance of $98 \%$, whilst a reflectance of $12 \%$ is achieved with the NPS1 surface structures.

The subsequent bead-on-plate welds on the generated surfaces show promising results. With all surface structures, the peak of reflected power that occurs during laser welding of
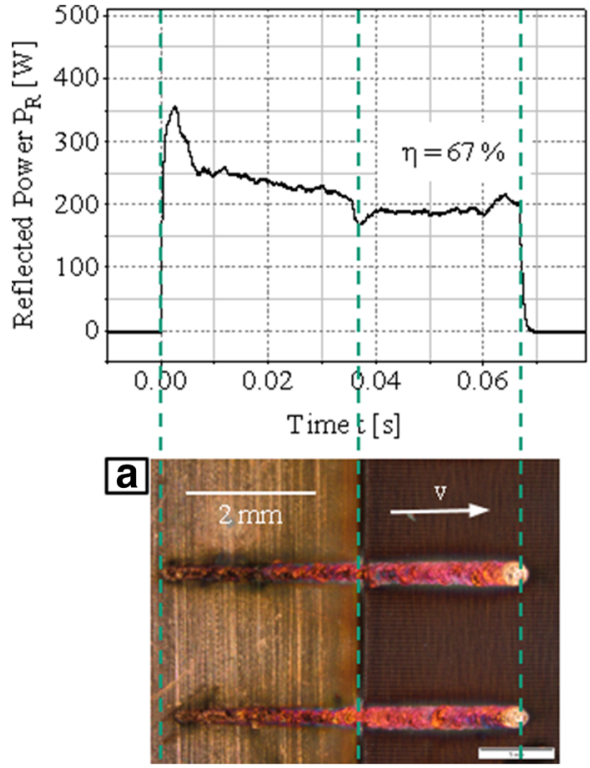
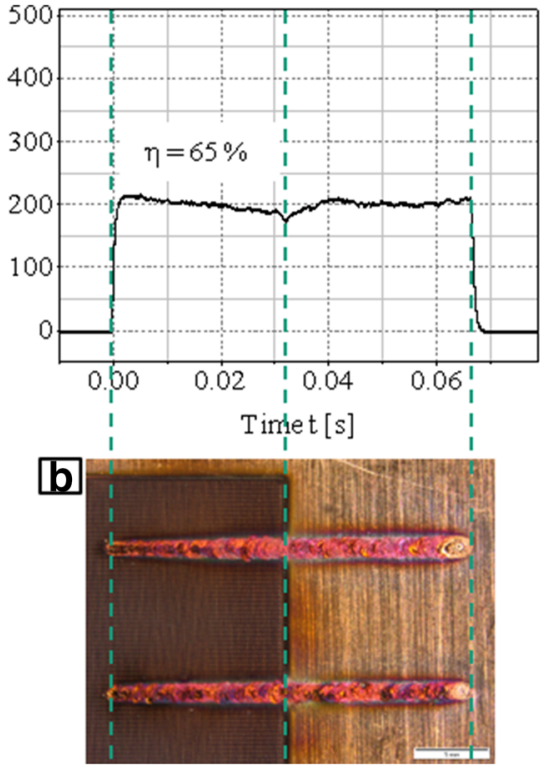

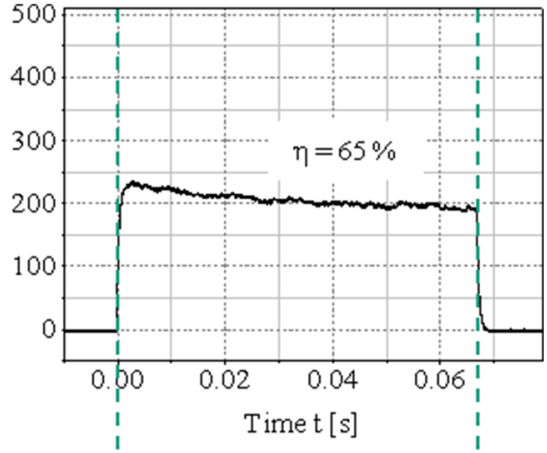

C

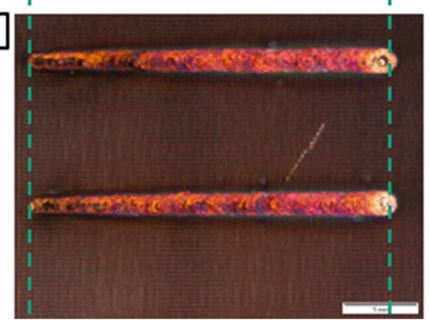

Fig. 11 Course of the reflected power $\mathrm{P}_{\mathrm{R}}$ of the PS2 samples over the weld seam length for weld seam positions A, B and C 

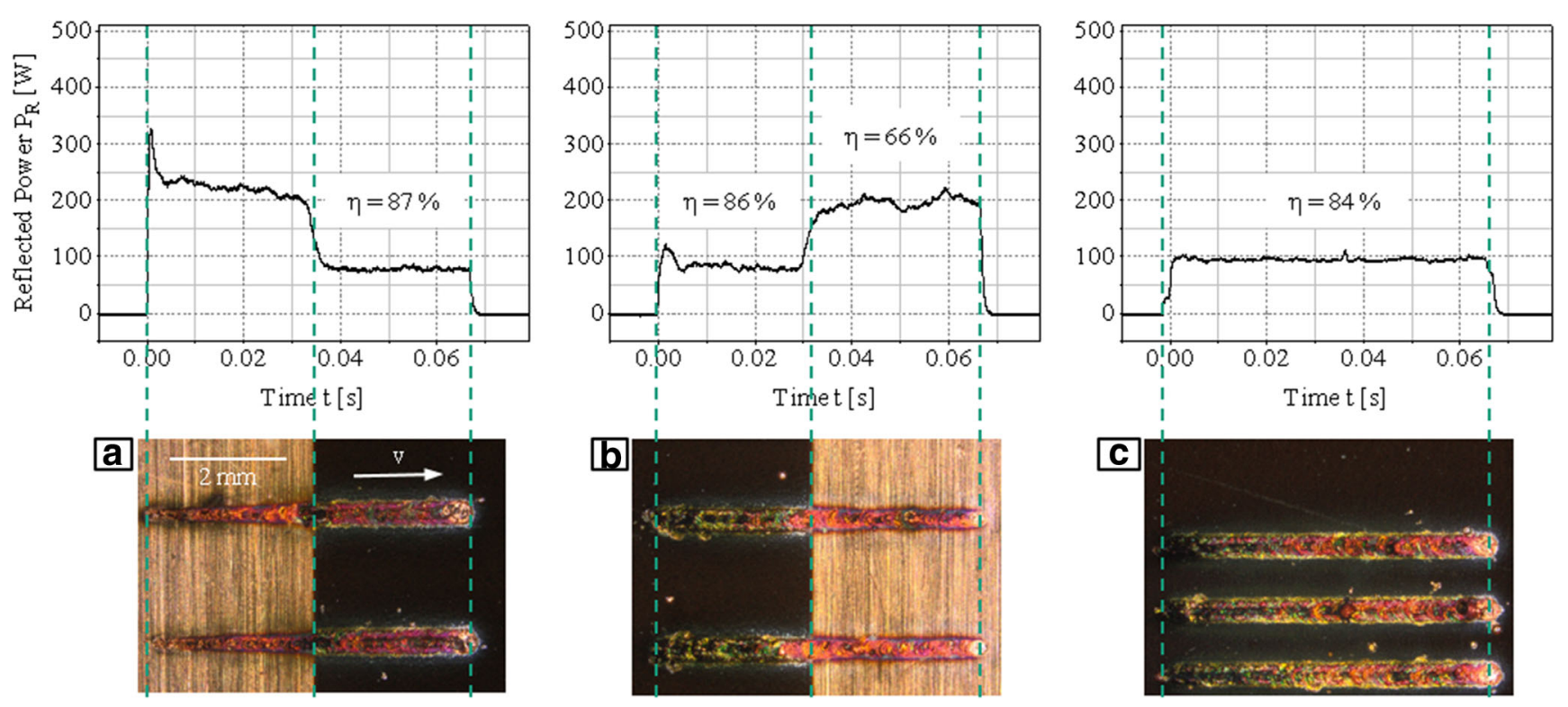

Fig. 12 Course of the reflected power $P_{R}$ of the NPS1 samples over the weld seam length for weld seam positions A, B and C

highly reflective materials such as copper at the beginning of the process can be significantly reduced or eliminated. This results in a faster transition to the deep penetration welding process. However, with the PS2 sample, no clear increase in the coupling degree can be detected during the entire welding process. The surfaces PS1, NPS1 and NPS2 also improve the coupling degree during the process. In addition, these surfaces show a more uniform and smoother process compared to an untreated surface.

In summary, the previous processing of copper surfaces with USP laser radiation can bring in more energy during laser beam welding. The generated surface structures can cause a faster transition to a deep penetration welding process as well as an increased energy input during the entire process.

\section{Further investigation}

In future investigations, the influence of the increased energy input by surface structures on the properties of the weld seam will be analysed. On the one hand, this includes a detailed investigation of the process sequence by high-speed videography in order to understand the effects and phenomena of welding on laser-structured surfaces. On the other hand, the resulting welds are characterized by metallographic investigations. Due to the increased degree of coupling, a deeper weld seam can probably be achieved on a laser-structured surface compared to untreated surfaces. Furthermore, it is possible to weld at a higher feed rate due to the increased degree of
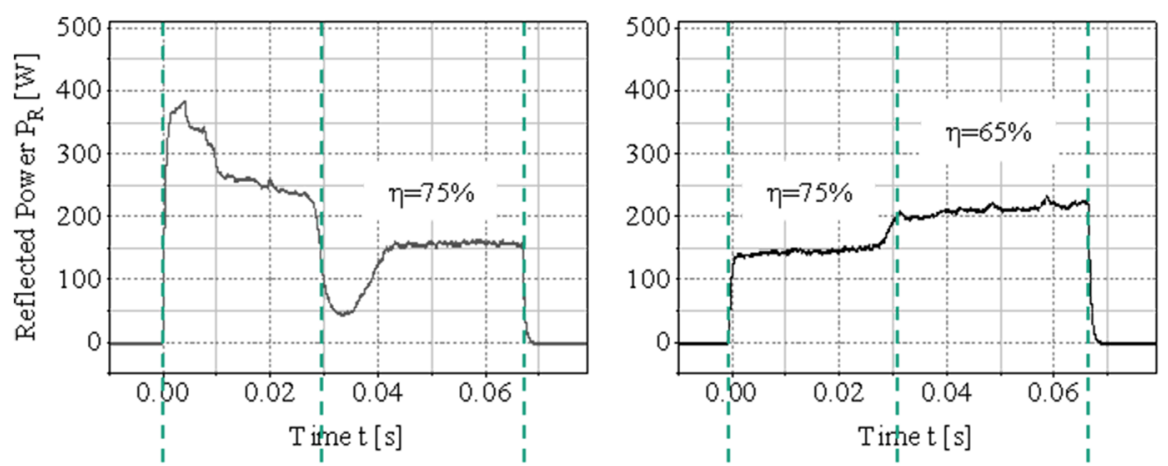

a

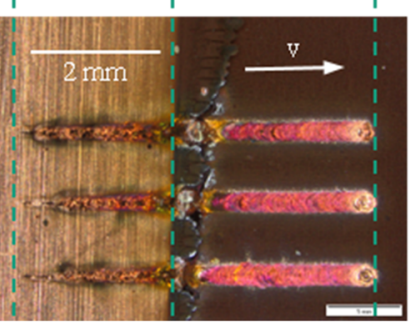

b

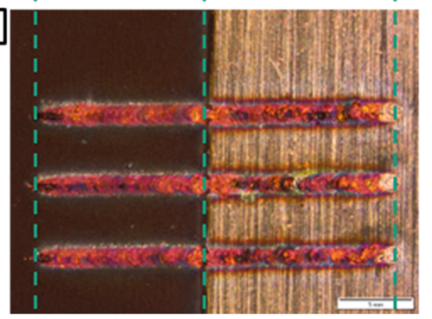

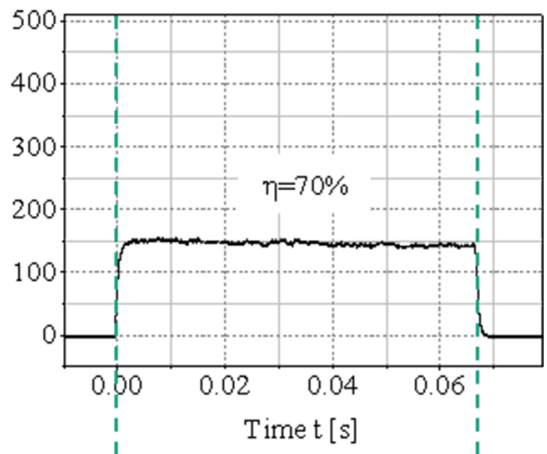

C

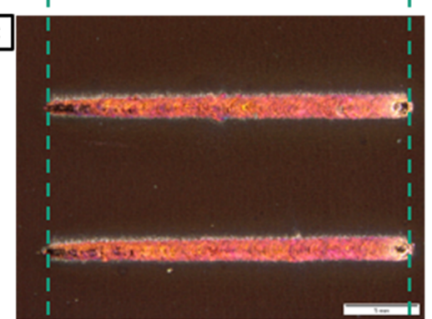

Fig. 13 Course of the reflected power $P_{R}$ of the NPS2 samples over the weld seam length for weld seam positions A, B and C 
absorption during the welding process, and thus significantly increase the production speed.

Another approach is the use of femtosecond or nanosecond lasers to structure the surfaces. Since there are already investigations on laser beam welding with nanosecond lasers, there is the possibility of a combined process in which the same laser is used for the laser structuring and the welding process.

Funding information This work was supported by the Federal Ministry for Economic Affairs and Energy in the frame of the FlexJoin project under the contract number 01MX15010B. Open Access funding provided by Projekt Deal.

Open Access This article is licensed under a Creative Commons Attribution 4.0 International License, which permits use, sharing, adaptation, distribution and reproduction in any medium or format, as long as you give appropriate credit to the original author(s) and the source, provide a link to the Creative Commons licence, and indicate if changes were made. The images or other third party material in this article are included in the article's Creative Commons licence, unless indicated otherwise in a credit line to the material. If material is not included in the article's Creative Commons licence and your intended use is not permitted by statutory regulation or exceeds the permitted use, you will need to obtain permission directly from the copyright holder. To view a copy of this licence, visit http://creativecommons.org/licenses/by/4.0/.

\section{References}

1. Umweltbundesamt (2018) Stickoxid-Belastung. https://www. umweltbundesamt.de/daten/luft/stickstoffdioxid-belastung\# textpart-1. Accessed 15 June 2019

2. Schmidt PA (2015) Laserstrahlschweißen elektrischer Kontakte von Lithium-Ionen-Batterien in Elektro- und Hybridfahrzeugen. Dissertation, TU München

3. Hügel H, Graf T (2009) Laser in der Fertigung. Vieweg+Teubner, Wiesbaden

4. Schmitt F (2012) Laserstrahl-Mikroschweissen mit Strahlquellen hoher Brillanz und örtlicher Leistungsmodulation. Dissertation, RWTH Aachen University

5. Chichkov BN, Momma C, Nolte S, Alvensleben F, Tünnermann A (1996) Femtosecond, picosecond and nanosecond laser ablation of solids. Applied Physics A 63:109-115. https://doi.org/10.1007/ bf01567637

6. Anisimov S, Kapeliovich B, Perelman T (1974) Electron emission from metal surfaces exposed to ultrashort laser pulses. J Exp Theor Phys 66:375-377

7. Corkum PB, Brunel F, Sherman NK, Srinivasan-Rao T (1988) Thermal response of metals to ultrashort-pulse laser excitation.
Phys Rev Lett 61:2886-2889. https://doi.org/10.1103/physrevlett. 61.2886

8. Perez D, Lewis LJ (2002) Ablation of solids under femtosecond laser pulses. Phys Rev Lett 89:255504. https://doi.org/10.1103/ physrevlett.89.255504

9. Zhigilei LV, Lin Z, Ivanov DS (2009) Atomistic modeling of short pulse laser ablation of metals: connections between melting, spallation, and phase explosion. J Phys Chem C 113:11892-11906. https://doi.org/10.1021/jp902294m

10. Zhigilei L (2003) Dynamics of the plume formation and parameters of the ejected clusters in short-pulse laser ablation. Applied Physics A 76:339-350. https://doi.org/10.1007/s00339-002-1818-5

11. Finger JT (2017) Puls-zu-Puls-Wechselwirkungen beim Ultrakurzpuls-Laserabtrag mit hohen Repetitionsraten. Dissertation, RWTH Aachen University

12. Poprawe R (2011) Tailored light. Springer, Berlin, p 2

13. Poprawe R (2005) Lasertechnik für die Fertigung: Grundlagen. In: Perspektiven und Beispiele für den innovativen Ingenieur. Springer, Berlin

14. Hartman CA (2013) Laserabtrag mit zeitlicher Modulation der Energiedeposition. Dissertation, RWTH Aachen University

15. Leitz A (2016) Laserstrahlschweißen von Kupfer- und Aluminiumwerkstoffen in Mischverbindungen. Herbert Utz Verlag Wissenschaft, Munich

16. Dilthey U (2006) Schweißtechnische Fertigungsverfahren 1: Schweiß- und Schneidtechnologien. Springer, Berlin

17. Heß A (2012) Vorteile und Herausforderungen beim Laserstrahlschweißen mit Strahlquellen höchster Fokussierbarkeit, Dissertation, University of Stuttgart

18. Conzen JH, Haeusler A, Stollenwerk J, Gillner A, Loosen P, Poprawe R (2018) Laserstrahl-Mikroschweißen von mikroelektronische Baugruppen unter Anwendung von örtlicher und zeitlicher Energiedeposition. Elektronische Baugruppen und Leiterplatten EBL 2018. In: Multifunktionale Aufbau- und Verbindungstechnik - Beherrschung der Vielfalt, 9. DVS/GMMFachtagung, Fellbach

19. Fan P, Zhong M, Li L, Huang T, Zhang H (2013) Rapid fabrication of surface micro/nano structures with enhanced broadband absorption on cu by picosecond laser. Opt Express 21(10):11628-11637. https://doi.org/10.1364/OE.21.011628

20. Fan P, Bai B, Zhong M, Zhang H, Long J, Han J, Wang W, Jin G (2017) General strategy toward dual-scale-controlled metallic micro-nano hybrid structures with ultralow reflectance. ACS Nano 11(7):7401-7408. https://doi.org/10.1021/acsnano.7b03673

21. Fan P, Zhong M, Bai B, Jin G, Zhang H (2015) Tuning the optical reflection property of metal surfaces via micro-nano particle structures fabricated by ultrafast laser. Appl Surf Sci 359:7-13. https:// doi.org/10.1016/j.apsusc.2015.10.069

Publisher's note Springer Nature remains neutral with regard to jurisdictional claims in published maps and institutional affiliations. 